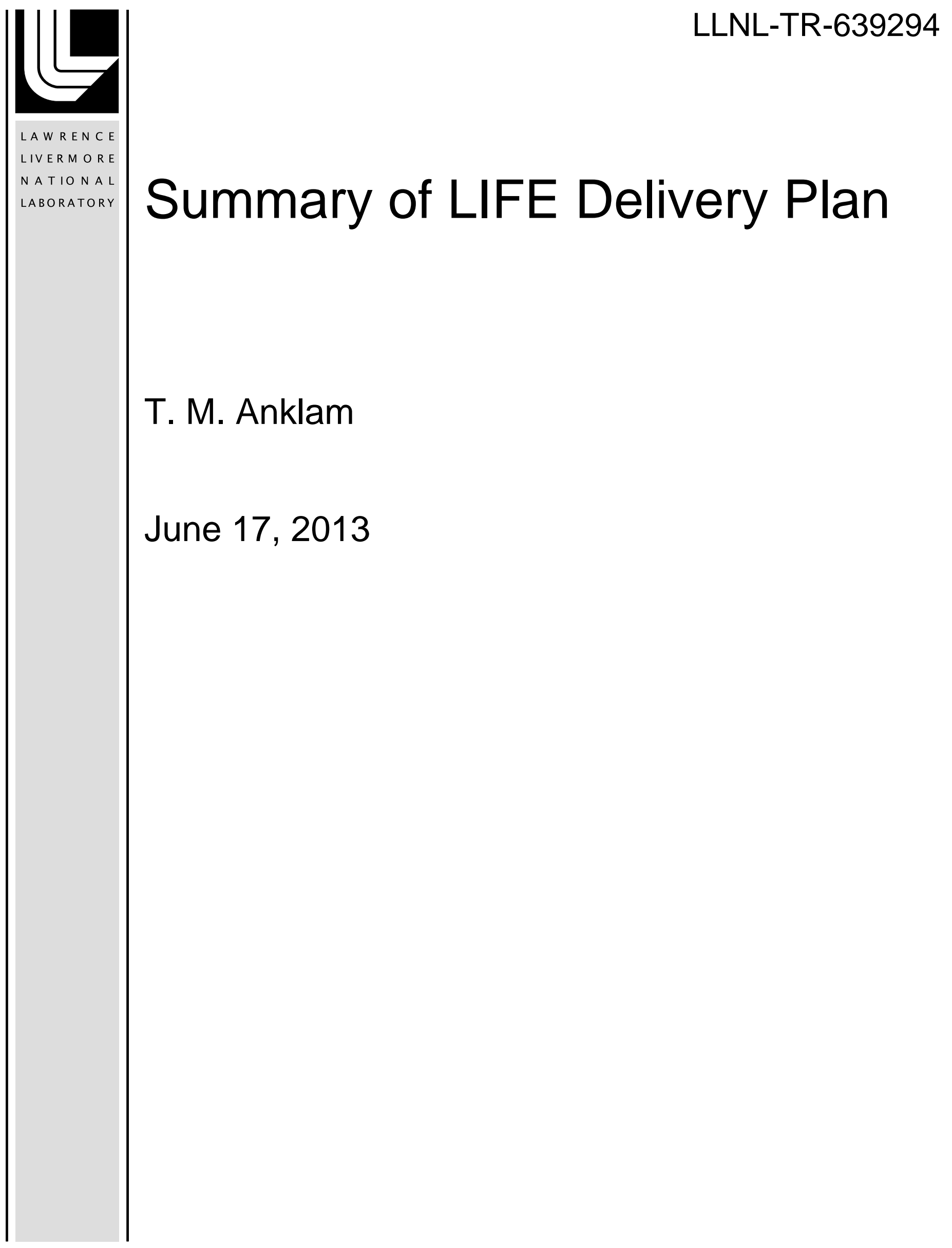


This document was prepared as an account of work sponsored by an agency of the United States government. Neither the United States government nor Lawrence Livermore National Security, LLC, nor any of their employees makes any warranty, expressed or implied, or assumes any legal liability or responsibility for the accuracy, completeness, or usefulness of any information, apparatus, product, or process disclosed, or represents that its use would not infringe privately owned rights. Reference herein to any specific commercial product, process, or service by trade name, trademark, manufacturer, or otherwise does not necessarily constitute or imply its endorsement, recommendation, or favoring by the United States government or Lawrence Livermore National Security, LLC. The views and opinions of authors expressed herein do not necessarily state or reflect those of the United States government or Lawrence Livermore National Security, LLC, and shall not be used for advertising or product endorsement purposes.

This work performed under the auspices of the U.S. Department of Energy by Lawrence Livermore National Laboratory under Contract DE-AC52-07NA27344. 


\section{Summary of LIFE Delivery Plan}

\section{Introduction}

The Laser Inertial Fusion Energy (LIFE) Delivery Plan describes the path from ignition on the National Ignition Facility (NIF) to operation of a demonstration LIFE power plant. This entails work scope structured along five primary areas:

- Reducing technology risk commensurate with key investment decisions.

- Designing, building and commissioning a demonstration power plant.

- Developing the safety basis and obtaining an operating license and permits.

- Developing the vendor base and ensuring a robust supply chain.

- Demonstrating that LIFE can function as an integrated power plant.

These areas are highly interrelated and require a rigorous systems approach and risk management process. As a national laboratory, LLNL's overarching goal is to conduct this endeavor in the public interest and to deliver the benefits of fusion energy in a timely way that addresses the energy, environment and security challenges that our nation faces today. To achieve this goal, the Delivery Plan is designed to reflect certain guiding principles:

- The fusion performance of the demonstration power plant must be demonstrated on the National Ignition Facility (NIF) at full scale.

- The power plant will be designed as a modular system so that the constituent technologies can be developed and demonstrated separately and in a parallel fashion.

- Power plant design will be fully integrated with the development of the regulatory process.

- The first power plant will be designed to maximize the use of technologies and materials that are available today, even if this implies lower initial performance and higher cost.

- The Delivery Plan must be structured so that those activities undertaken by the Laboratory support the core missions of the Laboratory.

- The project will partner with industry throughout the Delivery Plan, as most of the technology needed to build a fusion power plant exists outside of the national laboratory complex.

The Delivery Plan itself is organized along the lines of a 500 element work breakdown structure (WBS) that identifies all of the functional elements required to construct a LIFE power plant. Technology risks are identified, and work scope is defined to retire those risks in a manner that aligns with key investment decisions. A high level power plant design has been developed to provide a baseline for the Delivery Plan, and resource requirements have been estimated. Supply chain readiness has been evaluated and, where there are gaps, work scope has been developed to ensure a robust vendor base. 
This process was undertaken in partnership with a diverse set of industrial participants and other national laboratories where appropriate. Conventional systems designs and cost estimates were developed by Parsons Engineering and represent several years of concerted effort. Over 80 equipment vendors were involved in or informed the development of equipment cost estimates and procurement strategies. The overall design was informed by consultation with the utility sector and experts on environmental, sustainability and non-proliferation issues.

LIFE has important safety and environmental attributes when compared to nuclear fission or fossil-fueled power plants. A key criterion for success is a regulatory process that recognizes these differences and that reduces the uncertainty and cost of the licensing and permitting process. Our design concept and regulatory strategy is based on extensive discussion with licensing experts including recently retired senior officials from the Nuclear Regulatory Commission, a current public service and public utilities commissioner, and licensing and safety experts from private industry.

LIFE technical and project risk assessments, project schedules and risk mitigation plans were developed with the participation of the team that successfully delivered the NIF laser system, a project of similar size and technical complexity. Project management experience for construction of large power plants was added to the risk assessment team to address power plant design, construction, technology integration and commissioning issues.

\section{Delivery Plan Logic and Timeline}

The Delivery Plan is illustrated graphically in Figure 1. The Plan divides naturally into three primary phases: a programmatic development phase, a demonstration power plant project phase, and a power plant operations verification phase. Over the course of this process, the technology, design, operations, and regulatory bases required for rollout of the commercial fleet will be demonstrated. Durations of these phases is dependent on funding levels, rate of technical progress and other factors and so should be considered indicative.

Preparatory work to date for the Program Development phase has included a roughly four-year effort that has defined the design concept for a LIFE power plant; developed work scope, cost, and schedule estimates; and done exploratory analysis and experiments on key technical issues. In turn, these preparatory activities have built upon many years of plant design and technology development by the international community in this field and upon the experiences gained in building and commissioning the NIF. 


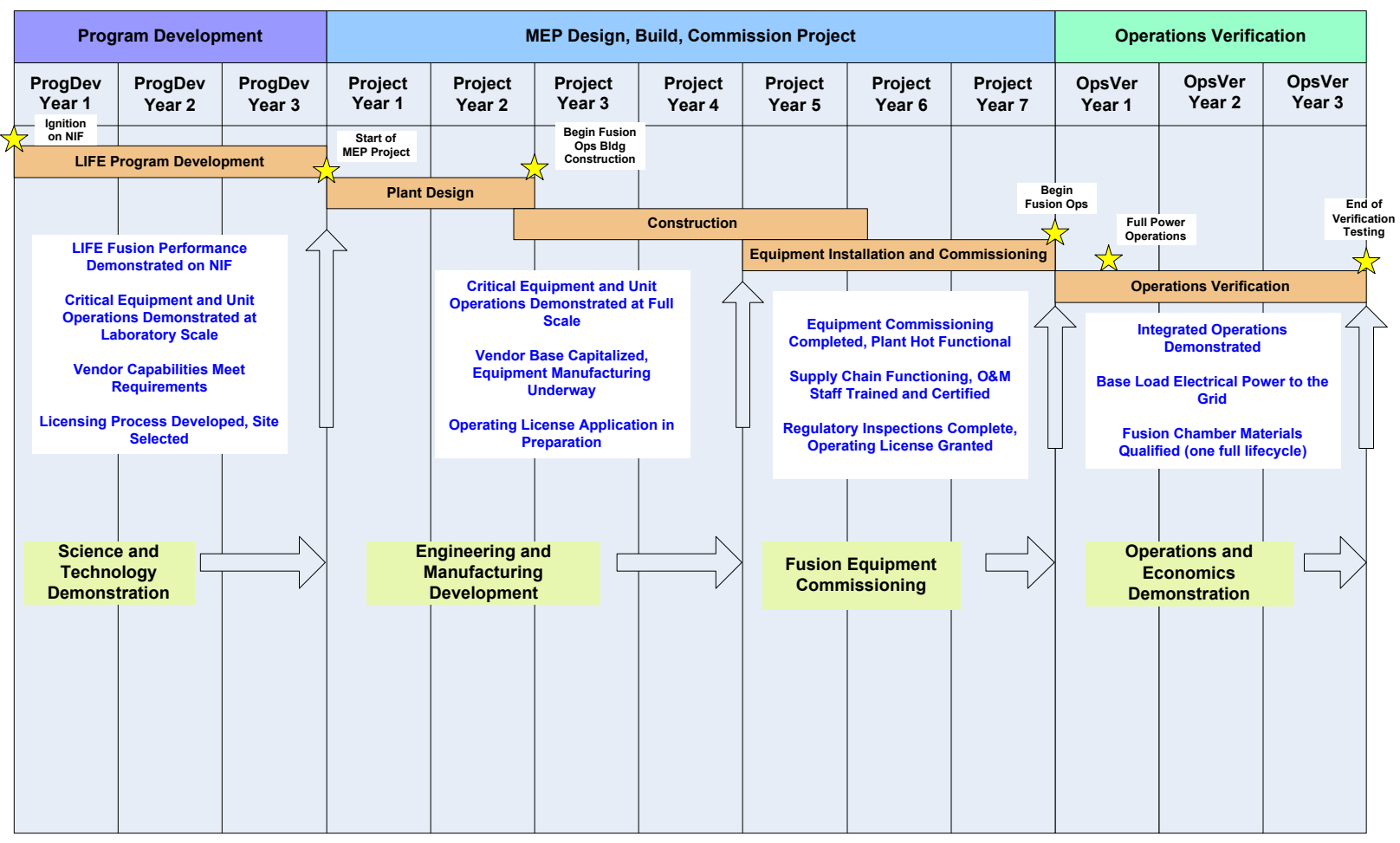

Figure 1. Delivery Plan schedule graphical illustration.

During the Program Development phase, the emphasis is on demonstrating the feasibility of the critical equipment and unit operations needed for a power plant. In most cases, these demonstrations will be at laboratory scale, but are essential in finalizing the design requirements for the plant equipment. A prototype of the LIFE fusion fuel will be fabricated using processes that can be scaled to production levels, and the prototype fuel will be tested on NIF. A vendor capability gap analysis has identified where capability enhancements will be required to procure demonstration plant equipment. Process and equipment development contracts will be established where there are gaps.

The Program Development phase will be a period of intense engagement with governing regulatory agencies to develop a regulatory and licensing framework for LIFE that recognizes important differences between the safety characteristics of LIFE and other generation technologies. Initial safety analysis and regulatory strategy development is already ongoing so that this key effort can begin without delay once a decision is made to formally approach the various regulatory agencies.

Other important outputs from the Program Development phase are the management, financial, intellectual property and governance arrangements for executing the demonstration plant project and the identification of the utility or merchant generator partner that will operate the demonstration plant, along with down-selection of the site. 
The focus of the Demonstration Plant project phase is the design, construction, and commissioning of the demonstration power plant (also known as the Market Entry Plant, MEP). Conventional construction is estimated to require about 42 months. During this time, critical equipment and unit operations required for the power plant will be prototyped and demonstrated at full scale. The vendor base will be capitalized as needed to support the required build rate, and plant equipment will be procured, installed, and commissioned. A construction authorization request will be submitted to the regulatory agency roughly coincident with the Project start. As plant turn-on approaches, there will be six months allocated for integrated plant commissioning, final regulatory inspections and worker training and qualification.

Regulatory approval to begin continuous fusion operations marks the beginning of the Plant Operations Verification phase. The Plant operating license will be based on certain assumptions about the gradual build-up of hazardous material in the Plant. An important element of this phase is to verify that actual inventory of material is bounded by assumptions used in the license application, such that worker safety and public safety can be rigorously maintained under all circumstances.

Durability of the fusion chamber in a fusion environment will also be verified, and the more radiation-resistant material to be used in the commercial fleet will be qualified through irradiation testing in the demonstration plant. Lessons learned from initial operations will be used to improve plant availability and transition to base-load generating operations.

At the completion of the three phases, the technology, design, operations, economic and regulatory bases required for the commercial fleet will have been established and demonstrated.

\section{Estimated Delivery Costs and Manpower Requirements}

Delivery costs are separated into the three time phases of the delivery plan and into a set of cost categories. The categorization is intended to separate the costs into groupings that are likely to have common funding and staffing strategies. Similarly, different phases of the delivery plan will likely attract different types of investors. During the Program Development Phase, technical risk is highest, but so are potential returns. This favors private investors with high-risk tolerance and/or government funding. As technical risk is retired, more conservative investors will likely move in to participate, and the need for direct government funding will decrease.

Most of the expertise needed to commercialize LIFE lies outside of LLNL and the DOE complex. As a result, commercialization of LIFE is being structured to maximize participation and investment by the private sector. If successfully commercialized, LIFE has enormous market potential. The potentially transformative nature of the technology will likely motivate major players in the energy field to invest resources to develop intellectual property (IP) and position for future market share. This is reflected in the high level of interest in LIFE that several major energy companies have shown, even prior to ignition on the NIF. Also, some of the 
technologies, such as the laser, have significant potential for spinoff markets. This would shorten the investment payback period and enable a more diverse pool of potential investors than would otherwise be the case.

Even with robust private sector investment, we would expect significant government participation. LIFE-related work in the NIF, laser system development, and advanced tritium processing technologies all offer significant benefit for government applications, so publicprivate partnering makes sense in these and several other areas. Developing the partnerships and funding portfolio required to execute the delivery plan is a major activity during the Program Development phase.

Technology development is expected to cost in the range of $\$ 1.2 \mathrm{~B}$ distributed over 5 to 7 years. In addition, roughly $\$ 400 \mathrm{M}$ will be required to develop needed manufacturing capabilities within the supply chain and $\$ 400 \mathrm{M}$ to ensure that there is adequate manufacturing capacity to supply the equipment and components needed for the demonstration power plant. This work would be performed by the same vendors who will ultimately supply the equipment needed for the followon fleet of power plants. In return for the market advantage that this would entail, it is expected that there will be significant opportunities for development cost sharing with the benefiting vendor community.

Design, build and commissioning of the demonstration power plant are estimated to cost in the range of $\$ 4.5 \mathrm{~B}$ to $\$ 6.5 \mathrm{~B}$. The Plant is initially designed to deliver between $400 \mathrm{MW}$ and $500 \mathrm{MW}$ to the grid. However, with an additional investment of $\$ 1 \mathrm{~B}$ to $\$ 1.5 \mathrm{~B}$, the Plant can be upgraded to just over $900 \mathrm{MW}$ output. This allows the first LIFE plant to transition from being a demonstration facility to a fully commercial power plant. Sales of electricity from the upgraded plant allow a significant offset of the costs to build initial demonstration plant.

From a market perspective, calculations of the cost of electricity (or process heat) from LIFE plants show the potential for highly competitive production, even ignoring the economics of externalities such as displaced emissions. Coupled to the inherent environmental, safety, geopolitical and sustainability benefits and the ability to produce power continuously, the investments required to establish a LIFE fleet have very clear market returns. 